\title{
La autobiografía lectora: una herramienta para la construcción de sentido en el quehacer docente*
}

\author{
Juan Camilo Tobón Cossio \\ BibloRed, Bogotá, Colombia \\ camilo.tobonc@gmail.com \\ https://orcid.org/0000-0002-8067-4552
}

\begin{abstract}
No tener miedo de las paradojas. Dejar de pensar en categorías y hacerlo en escenas, en imágenes, en metáforas, en relatos. Un pensamiento fragmentado, abierto, no sistemático, un pensamiento contrario a la lógica metafísica, una lógica que siempre tiene respuestas para todo y que, por eso mismo, nos aleja de la vida.
\end{abstract}

(Joan-Carles Mèlich, 2015)

\section{RESUMEN}

Los estudios de la didáctica de la lectura han encontrado en la investigación narrativa (el estudio de historias de vida), una herramienta para potenciar el quehacer y la reflexión sobre el rol del mediador de lectura, el papel de lectura en los procesos de formación y los desafíos que estas historias de vida generan en el panorama educativo. El presente artículo propone dar una mirada a estos elementos poniendo en diálogo el trabajo adelantado por investigaciones españolas y su desafío en el contexto latinoamericano, específicamente con la investigación propuesta por Bernal et al. (2018) en el escenario colombiano.

La investigación narrativa o estudio de historias de vida se puntualiza en una dinámica propia de los sujetos: el ser lec- tor. Al narrar la historia de lectura en lo que se denomina autobiografía lectora, se construye una conciencia del yo lector y se ahonda en las dinámicas que han marcado este camino, lo cual posibilitará a los docentes en formación y mediadores de lectura adoptar una postura crítica frente a sus dinámicas personales, la aplicación de sus didácticas y los planteamientos del sistema educativo. De este modo, la lectura rescatará su carácter de experiencia en donde el maestro o mediador toman como punto de partida su vivencia como lectores: su yo lector.

Palabras clave: promoción de la lectura; biografía; orientación para la lectura; yo lector.

Cómo citar: Tobón Cossio, J. C. (2020). La autobiografía lectora: una herramienta para la construcción de sentido en el quehacer docente. Ciencias Sociales y Educación, 9(17), 163-173. https://doi.org/10.22395/csye. v9n17a8

Recibido: 12 de noviembre de 2019.

Aprobado: 25 de febrero de 2020. 


\section{Reader's Autobiography: a Tool for the Construction of Sense in the Teaching Job}

\section{ABSTRACT}

The studies on the didactics of reading have found, thanks to narrative research (the study of life stories), a tool for improving the mediator role of reading, the role of reading in the formative processes, and the challenges that these life stories generate in the educational panorama. This article proposes a look to these elements by putting in dialogue the work started by Spanish researchers and the challenges for its continuity in Latin American, specifically for the research proposed by Bernal et al. (2018) in the Colombian scenario. The narrative research or the life stories study is pointed out in a dynamic propper to the subjects: being a reader. By narrating rea- ding stories in which is known as reading autobiography, a conscience of the reader self is built and deepens in the dynamics that have forged that path, which will make possible to the teachers in training and reading mediators and promoters to adopt a critical position towards their dynamics, the application of their didactics and the perspectives of the educational system. Thus, reading will rescue its experiential character in which the teacher or mediator takes as a starting point their own experience: their reading self.

Keywords: reading promotion; biography; reading orientation; reading self.

\section{A autobiografia leitora: uma ferramenta para a construção de sentido no fazer docente}

\section{RESUMO}

Os estudos da didática da leitura vêm encontrando, na pesquisa narrativa (o estudo de histórias de vida), uma ferramenta para potencializar o fazer e a reflexão sobre o papel do mediador de leitura, o papel da leitura nos processos de formação e os desafios que essas histórias de vida impõem no panorama educativo. Este artigo dá uma visão desses elementos e coloca em diálogo o trabalho realizado por pesquisas espanholas e seu desafio no contexto latino-americano, em específico com a pesquisa proposta por Bernal et al. (2018) no contexto colombiano. A pesquisa narrativa ou o estudo de histórias de vida está posicionada em uma dinâmica própria dos sujeitos: o ser leitor. Ao narrar a história de leitura no que se denomina "autobiografia leitora", constrói-se uma consciência do eu leitor e se aprofunda nas dinâmicas que vêm marcando esse caminho, o que possibilitará, aos docentes em formação e aos mediadores de leitura, adotarem um posicionamento crítico ante suas dinâmicas pessoais, a aplicação de suas didáticas e as propostas do sistema educacional. Desse modo, a leitura resgatará seu caráter de experiência em que o maestro ou mediador tomam como ponto de partida sua vivência como leitores: seu eu leitor.

Palavras-chave: promoção da leitura; biografia; orientação para a leitura; eu leitor. 


\section{Introducción}

Este texto tiene como interés hacer una presentación de dos obras que, desde el método de la investigación narrativa, abordan el estudio de la autobiografía del lector, la cual posibilita problematizar el quehacer docente y encontrar rumbos para la definición de sentidos en la adopción de este rol como camino vital del sujeto. Cabe anotar que las dos obras a las que haremos referencia en el presente escrito brotan en contextos que, si bien difieren de los colombianos y latinoamericanos, permiten contemplar elementos que potencian el oficio docente en el marco de la tarea siempre necesaria de la formación de formadores.

En el presente artículo se tendrá como punto de partida la reflexión realizada por Blanco (2011) para esbozar el concepto de investigación narrativa. En segundo lugar, se revisan dos ejemplos de la producción académica española, debido a que ha sido en España donde se ha liderado la producción documental en lengua castellana sobre el estudio autobiográfico, investigación narrativa o análisis de autobiografías lectoras para la formación de la subjetividad lectora y como mecanismo para la formación del profesorado. Universidades como la de Sevilla y la de Almería, y editoriales como Aljibe y Narcea, han abierto campo a la publicación y circulación de experiencias de esta índole. Cabe anotar que esta metodología ha encontrado repercusiones en investigadores de otras naciones como Brasil, México y Colombia, de las cuales solo se hará una breve mención.

En consecuencia con lo anterior, se abordarán las investigaciones de Granado y Puig (2015), y Padua y Prados (2014) para contar con un panorama de la cuestión y los desafíos que se lanzan desde el estudio autobiográfico a la formación de los presentes y futuros docentes.

Por último, el presente documento es fruto del trabajo de investigación que el autor ha desarrollado durante el proceso de investigación de la maestría en Didácticas, Lecturas y Literatura de la Universidad de San Buenaventura de Bogotá, así como de su labor como mediador de lectura en escenarios bibliotecarios y procesos de formación con docentes.

\section{La investigación narrativa}

Para comenzar, es conveniente hacer un acercamiento breve a la investigación narrativa. Esta es una metodología de investigación en el orden de lo cualitativo que permite tomar las historias de vida como horizonte de análisis, teniendo como punto de partida el hecho de que: "narrar la historia de una vida es una autointerpretación de lo que somos, una puesta en escena a través de la narración" (Moriña, 2017, p. 9). 
Aunque este método está en proceso de formulación teórica, representa aportes significativos en la búsqueda del sentido de la experiencia en la existencia del sujeto. Con respecto a esto, Blanco (2011) señala que, aún al final de la primera década del nuevo milenio, no hay una definición única de lo que se entiende por investigación narrativa. De ahí que sus practicantes ofrezcan visiones relativamente diversas. Sin embargo, uno de los elementos que la caracteriza y en torno al cual hay consenso es que la investigación narrativa tiene como eje de su análisis la experiencia humana, más específicamente "la investigación narrativa está dirigida al entendimiento y al hacer sentido de la experiencia" (Blanco, 2011, p. 139).

La investigación narrativa procura, en este orden, la dilucidación del sentido del ser y el quehacer relacionado con la historia de vida del sujeto, el cual, acompañado por otras historias de vida, construye la mirada de sí mismo como narración y establece los derroteros que definen su esencia y existencia. En este sentido, la investigación narrativa procura ir un poco más allá de otras metodologías que toman las historias de vida para la construcción de sentido, como puede ser el psicoanálisis o la logoterapia, en donde el sujeto es analizado como objeto que se construye desde la palabra y los sucesos puntuales de relación con los otros, pero con finalidades terapéuticas. Por el contrario, la metodología de la investigación narrativa busca una dinámica epistemológica en doble vía, en la cual tanto el individuo como la colectividad de individuos se construyen y delimitan mutuamente.

Los mismos especialistas aceptan que la investigación narrativa comparte una serie de características con otras formas o estilos de hacer investigación del enfoque cualitativo. Entre los más conocidos están los que se identifican como autobiografía y relatos de vida, y entre los nuevos estilos aparece la denominada autoetnografía. Estos géneros nos remiten, entre otras cosas, a la propuesta epistemológica que sostiene que "es posible leer una sociedad a través de una biografía". O como afirman los especialistas en la investigación narrativa: "los relatos son artefactos sociales que nos hablan tanto de una sociedad y una cultura como lo hacen de una persona o un grupo" (Blanco, 2011, p. 140).

Este tipo de investigación permite dilucidar el sentido de lo que se es, lo que se hace y lo que se anhela. Así, posibilita una reconstrucción de los relatos de vida del individuo que, al ser leídos en un conjunto (comunidad), aclaran las inquietudes individuales y colectivas que dinamizan la acción formativa, en este caso concreto, de los mediadores de lectura y docentes al profundizar en un elemento muy concreto de sus historias: las autobiografías lectoras. Dichas autobiografías como metodología serán tomadas por Padua y Prados (2014), y Granado y Puig 
(2015) como mecanismo para dotar de sentido el imaginario y el rol del docente en estudiantes que aspiran a formarse para ello.

\section{La autobiografía lectora como deconstrucción del imaginario docente: la propuesta de Padua y Prados (2014)}

La investigación titulada El uso de autobiografías en la formación inicial de los futuros docentes. Dos experiencias en la Universidad de Almería, fue generada con estudiantes que optan al título de docentes en Artes. Muchos de ellos, ante la imposibilidad de acceder a las carreras de su gusto y, para no perder la oportunidad de acceder a diferentes programas de educación superior, tomaron como última medida la formación como docentes.

La propuesta de las profesoras Padua y Prados (2014) consistió, en primera instancia, en dar un espacio para la escritura personal de las experiencias de los estudiantes, lo cual desembocó en la construcción de autobiografías lectoras, es decir, la redacción de las vivencias de su alumnado con las lecturas, emociones y vivencias que, por obligación o gusto, los acompañaron a lo largo de su historia en la institución formativa. En este sentido, afirman:

mediante el pensamiento narrativo [autobiografías] damos sentido a nuestra vida y a los sucesos en los que estamos involucrados integrándolos en relatos. Las biografías del alumnado contadas y elaboradas por ellos mismos es una herramienta metodológica que pone de manifiesto las relaciones que han establecido y las estructuras en las que han desarrollado sus procesos formativos. (Padua y Prados, 2014, p. 76)

Los resultados de este trabajo llevaron a que, en el proceso de relectura de los textos, tanto las docentes como su alumnado fuesen tomando una postura crítica frente a los procesos de formación escolar, la presentación y concepción de la escuela frente a la lectura, los textos propuestos en su canon y, finalmente, a cuestionar su futuro rol como docentes. Asimismo, la redacción, revisión y lectura en conjunto de dichas autobiografías permitió identificar confluencias en sus inquietudes de lectura (pedagogía crítica, pensamiento social, filosofía) y autores como Freire. Por último, los estudiantes encontraron afinidades al concebirse como lectores que se encuentran en capacidad de compartir lecturas o confluir en temas de interés.

La anterior experiencia encuentra relación en las palabras de Saramago (2007), quien insta a la generación de espacios de encuentro entre lectores quienes, al romper la soledad de la lectura, hallan otras resonancias, nuevas perspectivas de lectura y el encuentro empático que sustrae al lector de su solipsismo usual para la construcción de tejido social, comunidades de lectores quienes contribuyen a elaborar y reelaborar los sentidos de los textos y de la 
memoria. Esto quiere decir que el sujeto hace escritura y lectura del sí mismo como pasado y como proyecto, de modo que la autobiografía como texto común es una opción de futuro: de construir el docente y el lector que anhelan ser.

\section{La autobiografía lectora y su carga categorial para el análisis del ejercicio docente: la experiencia de Granado y Puig (2015)}

Ambas investigadoras aplicaron la propuesta de construcción de autobiografías lectoras con estudiantes de posgrado de la Universidad de Sevilla, quienes se encontraban en el ejercicio de tareas docentes. Según el artículo elaborado desde esta experiencia de construcción de autobiografías, es importante poner de manifiesto la posibilidad de la construcción de la historia de la vida de cada docente como lector:

Hay un camino que como lectores emprendemos en nuestra infancia y cuya trayectoria vendrá marcada por los libros que nos dieron a leer, por las tareas de lectura que tuvimos que abordar, por los modelos de lectores que conocimos, por el modo en que nuestras experiencias lectoras nos hicieron sentir. Los docentes tienen un papel fundamental en el trazado de esa andadura, pero a su vez ellos también han recorrido su propio camino como lectores. (Granado y Puig, 2015, p. 44)

Lo anterior representa, en primer lugar, una oportunidad para el asombro y la perplejidad, dado que no se suele reflexionar acerca de la identidad del sujeto en cuanto lector (Granado y Puig, 2015, p. 57) ni de las dinámicas históricas de esta realidad en la biografía personal y profesional. En segundo lugar, se busca evaluar el recorrido como lectores, es decir, establecer el corpus que se ha abordado (textos que se han retenido en el recuerdo), el que se proyecta (textos que acompañan el presente, los que se están leyendo) y el que falta por recorrer (textos que se anhela abordar en algún momento).

La experiencia relatada por Granado y Puig (2015) demarca un desafío para los investigadores de la autobiografía lectora como herramienta de análisis de la realidad lectora de los docentes en ejercicio. Dicho desafío elabora una serie de herramientas conceptuales y cuantitativas para establecer un aparato categorial en el que las historias de vida puedan ser analizadas, para que potencien los fines pedagógicos de la formación de docentes y lectores. En la definición de estas categorías (frecuencia, libertad, intensidad, comprensión, entre otras), que orientan la investigación desde los textos autobiográficos, es necesario estar atentos, pues dichos elementos de análisis surgen de la lectura atenta de los textos y de la detección de los elementos concurrentes, así como de los singulares. Por ello, el investigador ha de tomar decisiones puntuales por la carga categorial para la construcción de su investigación, la cual, como ya se ha esbozado, no puede ser a priori a la lectura de las autobiografías, sino como fruto de su reconocimiento. En este punto, el investigador también 
hace parte de la investigación al encontrar en las historias de vida y de lectura un detonante que cuestiona su propio camino como lector y formador de lectores.

\section{Diálogo de experiencias}

\section{Panopama español}

Las dos experiencias anteriormente presentadas son una breve muestra de cómo la investigación narrativa en el contexto español es una herramienta importante para la formación de docentes. Dicha perspectiva de investigación no solo ha marcado una inquietud reciente y amplia, sino también una tendencia que ha procurado la sistematización de relatos y la construcción de un paradigma de análisis que permite enriquecer las metodologías de estudio correspondientes a los métodos cualitativos asociados a las ciencias sociales, específicamente, para los estudios en el campo de la pedagogía, la formación de formadores y la didáctica de la lectura. En estos discursos - según lo presentado por las investigaciones anteriores - se ha permitido el fortalecimiento de la relación enseñanza-aprendizaje al posibilitar un diálogo con lo vivido y lo narrado, con las preocupaciones profundas, en últimas, con las historias de vida e identidad personal como profesional.

Otras obras de gran valor metodológico de origen ibérico son Moriña (2017) y Rivas et al. (2014), de las cuales pueden ser objeto de análisis posteriores en otros escenarios.

\section{Incorporación de la investigación autobiográfica en el contexto latinoamericano}

Como se ha presentado hasta el momento, en la península Ibérica se han multiplicado estas investigaciones en instituciones educativas. No obstante, en América Latina también se han encontrado documentos que reflejan la inquietud que genera esta metodología. A continuación, se mencionan algunos documentos que procuran teorizar o divulgar experiencias afines a la investigación autobiográfica para generar distintos fines formativos: Blanco (2011) en México, la cual procuró aportar en la sistematización teórica de este método. Por su parte, en Brasil, Trinidade Matías (2014) propuso el ejercicio de la redacción de autobiografías lectoras en la escuela para explorar mecanismos que propicien la participación ciudadana y un rol activo de los escolares en su trayectoria como lectores independientes. Finalmente, en Colombia, la investigación de Bernal et al. (2018) se propuso elaborar una revisión de las trayectorias de vida de algunos docentes en el contexto rural para contribuir a la formulación de estrategias que lleven a valorar en dichos docentes sus caminos como lectores para definir, desde sus propias memorias de vida, estrategias para la mediación de la lectura en sus contextos profesionales y personales. 
Lo anterior es una breve muestra de las resonancias que esta metodología y sus aplicaciones han generado en el continente americano. Este hecho permite entrever cómo la investigación autobiográfica no solo encuentra una oportunidad para la didáctica de la lectura aplicada a las aulas, sino también para los escenarios de mediación de la lectura no ligados del todo a la escuela, de apertura de caminos en todo el continente como mecanismo para la construcción de la memoria, la inserción en procesos de alfabetización y la construcción de comunidades de lectores que propician la formación de su autonomía en relación cercana con su cultura escrita, la tradición y su identidad (yo lector).

En la construcción de estas comunidades de lectores, las librerías, bibliotecas, centros de memoria, espacios de formación de formadores, clubes de lectura, tertulias, entre otros, proponen esta metodología de narración autobiográfica como una oportunidad de diálogo entre la inmensa producción bibliográfica y las historias de vida, entre los textos leídos y el afecto, el interés intelectual o la dificultad y el sentido. Así, se evidencia en estas historias algunos elementos, como la dificultad de acceso a los textos por motivos económicos, sociales o geográficos o su cercanía bajo diferentes formas.

Otra oportunidad que se presenta es ir configurando una comunidad de circulación de saberes que no solo parta desde el conocimiento teórico, sino también desde la experiencia del yo que lee, del yo que da sentido: el yo lector. Sobre este ejercicio de narración autobiográfica en escenarios paralelos a la escuela, el trabajo de Agudelo y Naranjo (2019) resulta revelador y conmovedor.

\section{Desafíos y oportunidades de la herramienta de la autobiografía lectora para la formación docente}

La estrategia de construcción de autobiografías lectoras dentro de la investigación narrativa plantea, como se ha visto hasta el momento, diferentes desafíos en la ruta de la formación docente. De estos desafíos se presentarán tres como cierre de este artículo: hacer sentido, autorreconocimiento y la evaluación de nuestras prácticas.

\section{Hacer sentido}

Al volver sobre lo vivido y elaborar estas vivencias desde una óptica muy específica como lo es la autobiografía lectora, se abre una puerta para la perplejidad del sujeto. Perplejidad que, desde una perspectiva epistemológica y existencial, le conduce al cuestionamiento de sus prácticas personales como colectivas, es decir, a los elementos que van constituyendo su identidad como lector (yo lector); su protagonismo o pasividad en el camino lector; sus niveles de lectura y los libros o autores que aún faltan por abordar; así como la mediación que ejerce o no sobre dichos textos. Lo anterior se hace para llevar a preguntas como 
¿por qué leer?, ¿para qué hacerlo?, ¿qué se pretende con la valoración o subvaloración que de las prácticas de lectura se dan en el ejercicio docente?

\section{Autorreconocimiento como lectores}

Las investigaciones presentadas en este escrito permiten notar que los docentes, en cuanto mediadores de lectura, presentan preocupaciones didácticas frente al desarrollo de competencias lectoras: "cómo hacer que mis estudiantes lean" (Bernal et al., 2018), pero soslayan su propia experiencia como lectores. En algunos casos, el quehacer repetitivo, la falta de estímulos y las exigencias administrativas desdibujan su identidad como lectores. Es importante detener la marcha y revisar los textos que han marcado su existencia, que han sembrado inquietudes replicadas en el quehacer científico, investigador o docente para definir una posible ruta de formación desde la primera persona y provocar la pasión por la palabra. Si desde esta primera persona (yo lector), se reconoce como un ser inmerso en la experiencia de la palabra y el acto de leer no le es ajeno ni distante en su devenir histórico, la mediación de la lectura podrá adquirir otro matiz: el de un hacer cercano a su vida.

La autobiografía lectora, en el sentido anterior, permite que los docentes y futuros docentes se reconozcan como lectores y valoren sus posibilidades, aportes como personas que encuentran en el acto de leer uno de los elementos que nutren su vida personal, intelectual y su oficio profesional. Llama la atención que algunos docentes no dimensionaban su camino como lectores y sus afinidades con otros lectores o escritores de sus propias vidas antes de este ejercicio.

\section{Evaluación de las prácticas de lectura en el orden de lo personal y la mediación}

La investigación narrativa, al proponer un ejercicio de escritura de la memoria del camino lector, propone a quien escribe su autobiografía lectora cuestionar su vida como lector y, para el caso de docentes en ejercicio o en proceso de formación, replantear los mecanismos de mediación de lectura. La objetivación de esta historia por medio de un texto permite que la misma vida se haga lectura personal y para otros, lo cual posibilita también que, en el sentido que se dé a lo vivido, se descubra lo que se ha denominado identidad lectora: yo lector.

En esta evaluación del ser como lector, se generan posibilidades de discernimiento para presentar la lectura en el aula. Con ello, los docentes podrán tomar una postura frente a la invitación de "dar de leer" (Pennac, 1992), donde el placer y el deber de aprender —o enseñar- se presentarán como una tensión en la cual los criterios del docente se pondrán en juego para su autodeterminación como mediador de lectura. 
Se abre, en este sentido, un camino de reflexión para el mediador, quien ha de oscilar entre ser receptor de la experiencia personal de la lectura y propiciador de la misma en otros. A propósito de esto, al referirse a la lectura de la literatura infantil y, por extensión, a la experiencia de lectura en general, Bernal et al. (2018) indican:

[...] el mediador de lectura, debe descubrirse también como un destinatario de la literatura infantil en primera persona como un yo lector. Yo lector que se descubre como un sujeto inacabado, que entabla relaciones de aprecio o desagrado con diferentes obras, como agente activo y pasivo del quehacer literario: activo, en la medida que propone perspectivas de lectura de un texto, que fomenta el encuentro entre lectores y postula relaciones con otras obras o asuntos; pasivo, en la medida que debe detenerse, esto es, silenciarse, para recibir los afectos y efectos de un libro que interpela a su soledad. Este yo lector inacabado, relee su transitar por el mundo de los libros y descubre en el canon de sus propias lecturas, las relaciones que lo proyectan a narraciones nuevas en las que él es un texto a leer, es decir, una posibilidad de narración y de escritura. (p. 28)

\section{Conclusiones}

En conclusión, la investigación narrativa se presenta como una metodología de orden cualitativo dentro de las ciencias sociales. Cuenta con elementos valiosos para indagar en el trasfondo de la historia personal y los sustentos de la didáctica de la lectura y la literatura que cada docente — mediador de lectura - formula a lo largo de sus años de formación como lector, pedagogo y didacta, pues propone la oportunidad de la redacción de la historia de vida en relación con la lectura, lo que se denomina autobiografía lectora. Estas autobiografías lectoras, al ser un ejercicio que objetiva las experiencias de lo vivido, son los elementos que subyacen en la investigación narrativa. En este sentido, lo aplicado a las prácticas pedagógicas es una puerta abierta para perfilar las dinámicas de la escuela y optar por estilos que no pueden abrirse sin antes hacer un autorreconocimiento del yo lector del mediador. En este orden, las investigaciones adelantadas en España han planteado perspectivas para la teorización de esta herramienta, así como ejemplos de implementación en el campo de la formación de docentes en ejercicio y en formación.

\section{Agradecimientos}

Artículo producto de la investigación Autobiografía lectora y mediación: una propuesta pedagógica para normalistas en formación (trabajo de maestría) de Beltrán et al. (2019), Universidad de San Buenaventura, Bogotá (2020), adscrita al Grupo de Investigación Tendencias Actuales en Educación y Pedagogía (Taepe), en la línea de investigación Antropología Pedagógica y Desarrollo Humano. 


\section{Referencias}

Agudelo, O. y Naranjo, J. (2019). Lo que mi voz leía -cartas-. Fondo editorial Universidad Eafit.

Bernal, J. E., Castiblanco, J., Sacristán, F. E. y Tobón, J. C. (2018). La literatura infantil como escenario para la formación de formadores [tesis de especialización, Universidad San Buenaventura, Bogotá]. Repositorio institucional USB. http://biblioteca.usbbog.edu.co:8080/Biblioteca/BDigital/169659.pdf

Blanco, M. (2011). Investigación narrativa: una forma de generación de conocimientos. Argumentos. Estudios críticos de la sociedad, (67), 135-156. https://argumentos.xoc.uam.mx/index.php/argumentos/article/view/278

Granado, C. y Puig, M. (2015). La identidad lectora de los maestros en formación como componente de su identidad docente. Un estudio de sus autobiografías como lectores. Ocnos. Revista de estudios sobre lectura, 13, 43-63. https://doi.org/10.18239/ocnos_2015.13.03

Mèlich, J-C. (2015). La Lectura como plegaria. Fragmenta.

Moriña, A. (2017). Investigar con historias de vida: metodología biográfico-narrativa. Narcea.

Padua, D. y Prados, M. (2014). El uso de autobiografías en la formación inicial de los futuros docentes. Dos experiencias en la Universidad de Almería. En J. Rivas, A. Leite y E. Prados (coords.), Profesorado, escuela y diversidad: la realidad educativa desde una mirada narrativa (pp. 75-93). Ediciones Aljibe.

Pennac, D. (1992). Como una novela. Norma.

Trinidade Matías, Th. (2014). Autobiografia na escola: história(s) de leitores e de vida. Alfal 2014 (1819). http://www.mundoalfal.org/CDAnaisXVII/trabalhos/R0558-1.pdf

Rivas, J. I., Leite, A. E. y Prados, E. (2014). Profesorado, escuela y diversidad: la realidad educativa desde una mirada narrativa. Ediciones Aljibe.

Saramago, J. (2007). Palabras para un mundo mejor. Alcaldía Mayor-Libro al viento. 